\title{
Assessment of genetic diversity using DNA markers among Brassica rapa var. yellow sarson germplasm lines collected from Eastern Uttar Pradesh and Uttarakhand hills
}

\author{
Harsha $^{1 *}$, Jitendra Kumar Meena ${ }^{2}$, Ram Bhajan ${ }^{1}$, Usha Pant ${ }^{1}$ and Mohammed Talha ${ }^{1}$ \\ ${ }^{1}$ Department of Genetics and Plant Breeding, G .B. Pant University of Agriculture and Technology, Pantnagar, \\ U.S.Nagar,260314(Uttarakhand), INDIA \\ ${ }^{2}$ Division of Genetics, IARI, New Delhi-110012, INDIA \\ *Corresponding author. E-mail: harshrewasia325@gmail.com
}

Received: October 07, 2015; Revised received: May 10, 2016; Accepted: July 24, 2016

\begin{abstract}
The genetic diversity and the relatedness among thirty-one germplasm lines of yellow sarson collected from eastern UP were evaluated using morphological characters and Random Amplified Polymorphic DNA (RAPD) markers. Molecular parameters, viz. A total number of bands, average polymorphic band, average percent polymorphism, average polymorphic information content (PIC), Jaccard's similarity coefficient, Principal Coordinate Analysis (PCA) and dendrogram generated using RAPD markers. A total of 148 different polymorphic amplification products were obtained using 10 selected decamer primers. The Jaccard similarity coefficient ranged from 0.557-0.899. Maximum polymorphism detected was $100 \%$. The range of amplification was from 190bp to $9 \mathrm{~kb}$. Some unique bands were also reported with different primers that can be used for the identification of particular accession. PYSC-11-11 and PYSC-11-36 genotypes showed a maximum number of unique loci of different size. 31 germplasm lines grouped into two major clusters I and II based on RAPD profiling. Morphological characterization was done on the basis of leaf, petal and beak characteristics. The similarity value among the germplasm lines ranged from 0.222 to 1.000 using morphological descriptors. The dendrogram generated grouped the germplasm accession into two major groups at $44 \%$ similarity value. The cluster analysis was comparable up to some extent with Principal Coordinate Analysis (PCA) of two and three-dimensional plots. The variability revealed by morphological and molecular profile were found to be non-comparable. This study indicated the presence of high genetic diversity among collected yellow sarson germplasm, which could be used for developing for breeding and germplasm management purposes.
\end{abstract}

Keywords: Brassica rapa, Genetic diversity, PCA, RAPD

\section{INTRODUCTION}

Rapeseed-mustard is an important crop with great economic value in worldwide. Brassica juncea (Indian mustard) and B. rapa are the important oilseed crops in India. The B. rapa is divided into three ecotypes, viz., toria, brown sarson and yellow sarson which are grown in India. Among Brassica rapa var yellow sarson is grown since ancient time due to the presence of a comparatively higher percentage of oil in the seed, shorter crop duration and attractive seed coat colour. Northeastern India is considered as primary centre of origin, however, genetic diversity found in eastern Uttar Pradesh and West Bengal (Misra, 2011)

Assessment of genetic variability present in the available germplasm is the first step in any crop improvement programme. The collected information on the genetic diversity in $B$. rapa var yellow sarson could help breeders and geneticists to understand the structure of $B$. rapa var yellow sarson germplasm and help them to evaluate which combinations would produce the best offspring. Accurate assessment of the levels and patterns of genetic diversity have diverse applica- tions, viz. (i) analysis of genetic variability in cultivars, (ii) identifying diverse parental combinations to create segregating progenies with maximum genetic variability for further selection and (iii) introgressing desirable genes from diverse germplasm into the available genetic base. There are various techniques available, which allow studying the genetic variability of crop germplasm. Morphological traits, total seed proteins, isozymes and several types of DNA markers are wellknown examples. DNA-based molecular marker techniques are being used enormously for estimating the magnitude of diversity (Abbas et al., 2009). However, molecular markers reveal differences of natural sites at the DNA level. These variations are not seen in the phenotype and each might be single nucleotide differences in a gene or a piece of repetitive DNA (Chen et al., 2011). Moreover, molecular markers are not subject to any environmental fluctuations, making them specifically informative and superior to conventional methods of genotyping such as the use of morphological traits and biochemical markers (Gupta et al., 1999). Molecular marker techniques include restriction fragment length polymorphisms (RFLPs) (Beckman and ISSN : 0974-9411 (Print), 2231-5209 (Online) All Rights Reserved @ Applied and Natural Science Foundation www.jans.ansfoundation.org 
Soller, 1983), simple sequence repeats (SSRs) or microsatellites (Tautz, 1989), random amplification of polymorphic DNA (RAPDs) (Williams et al., 1990; Welsh and McClelland, 1990; Karp et al., 1997) and amplified fragment length polymorphisms (AFLPs) (Vos et al.,1995).

Among molecular markers, random amplified polymorphic DNA (RAPD) has been employed in genetic research owing to their speed and simplicity (Welsh and McClelland 1990) RAPD analysis has been widely used in recent studies on Brassica crops: (1) for determining the genetic relationships between different related species (Demeke et al., 1992, Thormann et al., 1994 and Ren et al., 1995), (2) for the identification of cultivars (Quiros and $\mathrm{Hu}$ 1991) and the percentage of hybridity (Marshall et al. 1994), (3) for the estimation of genetic relationships and diversity among crop germplasm (Kresovich et al. 1992, Mailer et al. 1994, Santos et al. 1994, Divaret and Thomas 1998). RAPD marker has been extensively used for diversity analysis in various crops (Saha et al., 2008 studied the Genetic relationship between four Brassica varieties using RAPD markers, Ghosh et al., 2009 analysed the Genetic diversity through RAPD markers in Brassica varieties in Bangladesh, Khan et al., (2011) used RAPD in Brassica juncea, Gupta et al., (2014) used RAPD markers in Indian Mustard for analysis of Genetic variation, and Yousuf et al., (2012) also used RAPD marker for comparative studies between Indian mustard varieties.

It is, therefore, the aim of this work was to provide genetic variation and relatedness among the yellow sarson germplasm lines by PCR-based RAPD technique, as it is important particularly for selection of diverse parents to be used in a hybridization programme.

\section{MATERIALS AND METHODS}

Plant material: The experimental material comprised of 31 yellow sarson germplasm lines including two checks viz; PPS-1 and B-9. The germplasm lines were collected from Eastern Uttar Pradesh and Uttrakhand hills. Various parameters related to morphology characterization viz; like petal length, petal width, leaf length, leaf width, leaf lobes, the number of leaf lobes, leaf hairiness and beak length were recorded as per the DUS (Distinctness, Uniformity and Stability) guidelines during rabi season 2012-13 following random block design (RBD) with three replications.

Total DNA isolation and RAPD fingerprinting: Total cellular DNA was isolated from freshly germinated young leaves following the CTAB method of Murry and Thompson (1980) with following modification: about 3 gm of 4-5 days fresh germinated seedlings tissue was crushed to powder in liquid nitrogen and transferred to pre-warmed $\left(65^{\circ} \mathrm{C}\right) 2 \mathrm{xCTAB}$ buffer. The DNA was purified by phenol-chloroform extraction and ethanol precipitated. The final DNA pellet was dissolved in TE buffer was stored in $-20^{\circ} \mathrm{C}$ until use. An initial screening of 15 random primers was performed in order to evaluate their capacity to produce polymorphic, reproducible and reliable RAPD patterns. Ten primers were selected among them for molecular diversity analysis.

DNA amplification: Polymerase chain reaction was performed based on the protocol of Williams et al. (1990), with minor modification. Amplification was carried out in $25 \mu \mathrm{l}$ of reaction mixture containing 2.5 $\mu 1$ reaction buffer (10X), $2.0 \mu \mathrm{l}$ dNTPs mixes $(200 \mu \mathrm{M}$ each), $2 \mu \mathrm{l}$ (40 ng $\left.\mu \mathrm{l}^{-1}\right)$ decamer primer, $2 \mu \mathrm{l}\left(40 \mathrm{ng} \mu \mathrm{l}^{-}\right.$ $\left.{ }^{1}\right)$ genomic DNA and $0.5 \mu \mathrm{l}\left(3 \mathrm{U}_{\mu 1} \mathrm{l}^{-1}\right)$ Taq DNA polymerase was used for the amplification of template DNA. PCR reactions were performed with Bio-Rad thermocycler. PCR programme had an initial denaturation at $94^{\circ} \mathrm{C}$ for $4 \mathrm{~min}$, denaturing at $94^{\circ} \mathrm{C}$ for $1 \mathrm{~min}$, annealing at $36^{\circ} \mathrm{C}$ for $60 \mathrm{sec}$ and polymerization at $72^{\circ} \mathrm{C}$ for $2 \mathrm{~min}$ and final extension $72^{\circ} \mathrm{C}$ for $10 \mathrm{~min}$. After amplification, the PCR product was resolved on $1.5 \%$ agarose gel in $1 \mathrm{X}$ TBE buffer. The gel was visualised under UV using gel documentation system.

Data analysis: All polymorphic bands were scored as (1) for presence and (0) for absence. Only reproducible and reliable bands were scored for all the genotypes and primer combinations. The data was analysed using NTSYS pc 2.02 (Numerical Taxonomy System) software. Similarity Jaccarrd coefficient computed. Cluster analysis was done and a dendrogram was constructed using unweighted paired group of the arithmetic mean (UPGMA) algorithm. The structure of the genetic diversity was further analysed by Principal Coordinate Analysis (PCA) from the correlation matrix among the markers. Both cluster analysis and PCA were performed using NTSYS pc 2.02 statistical software.

\section{RESULTS AND DISCUSSION}

Morphological description: During the present study morphological characterization was done on yellow sarson germplasm lines and the data was recorded as per the DUS( Distinctness, Uniformity and Stability) guidelines. Similarity matrix and a dendrogram were generated using NTSYS pc 2.02 software. The value of similarity matrix for morphological characterization ranged from 0.222 to 1.000 . B-9(1.000) was found to be most diverse from PPS-1(0.222) and PYSC-11-29 (0.222). The dendrogram generated using NTSYS 2.02 grouped the germplasm accession into two major groups at $44 \%$ similarity value. Cluster I have four lines namely PYSC-11-5, PYSC-11-29, PYSC-11-39 and PPS-1. Rest all the lines fall in the cluster II (Fig.3.). Yassein et al. (2013) also used the morphological traits for the purpose of genetic diversity and heritability analysis in B.napus in Egypt.

Molecular profiling: Ten primers were selected to amplify total DNA from samples of all genotypes which showed $100 \%$ polymorphism. A total 148 repro- 
Harsha et al. / J. Appl. \& Nat. Sci. 8 (3): 1333 - 1340 (2016)

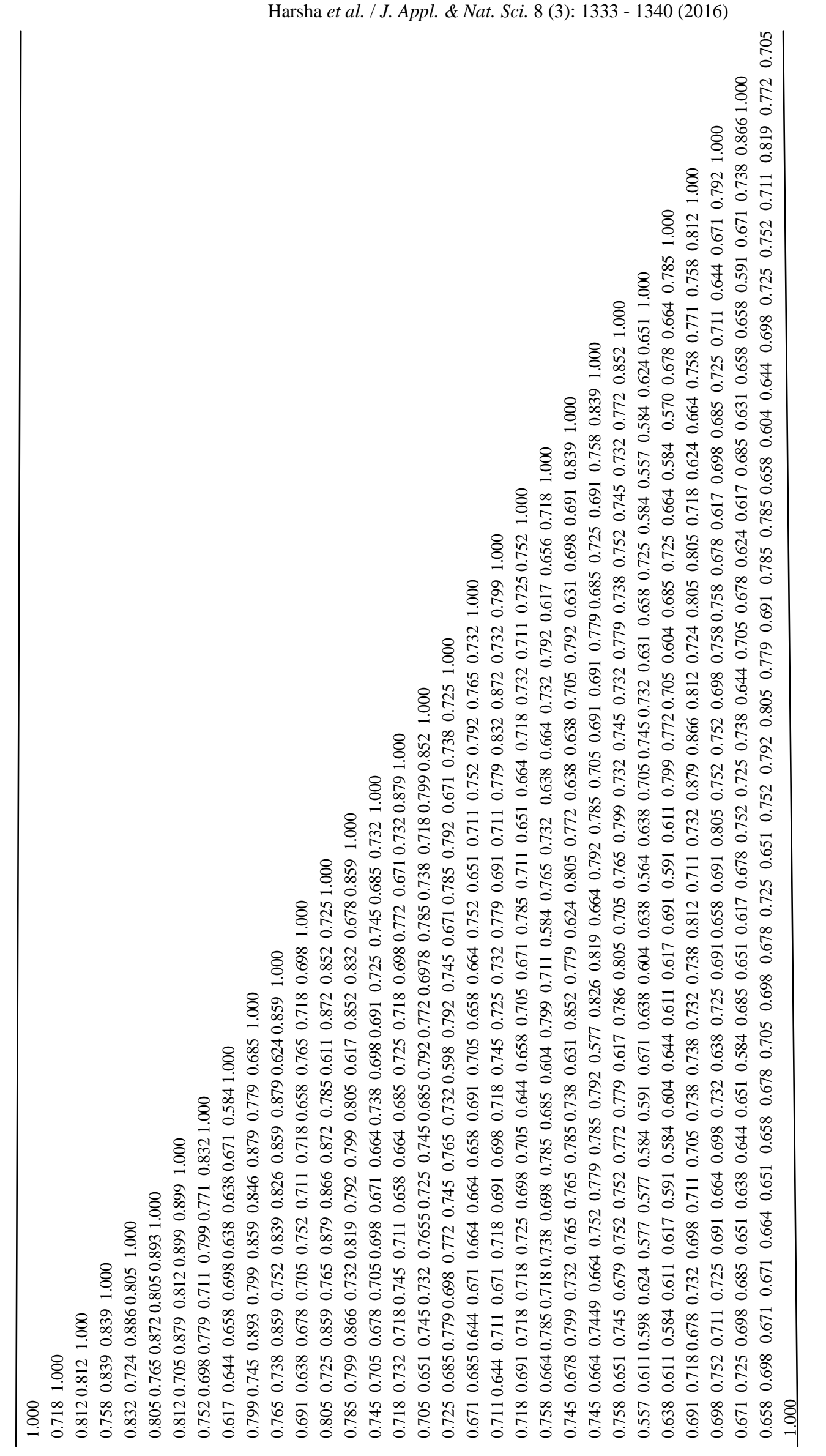

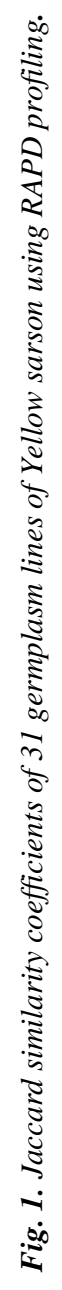




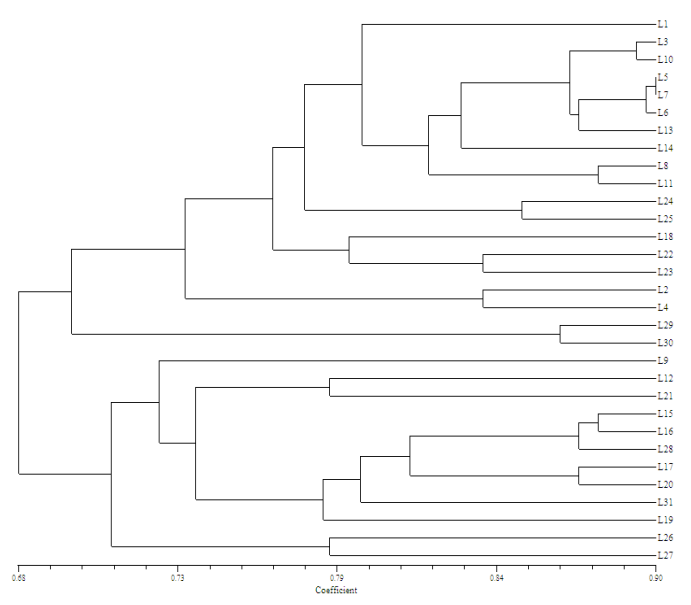

Fig.2. Dendogram derived from UPGMA cluster analysis using RAPD profile.

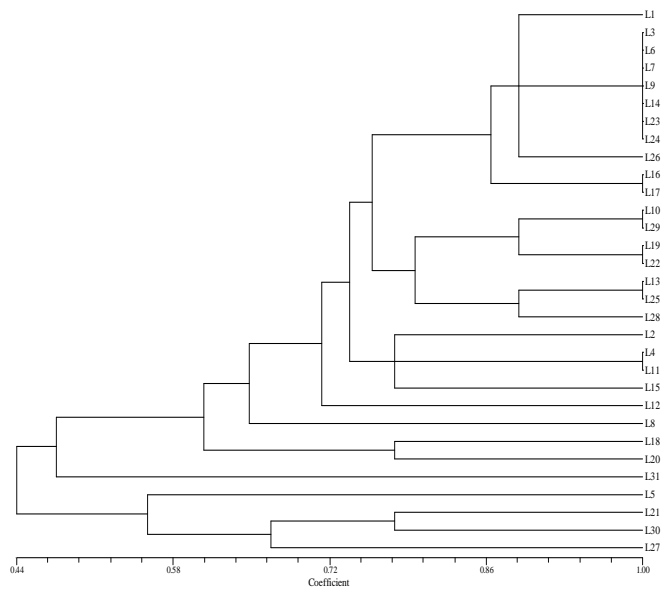

Fig.3. Dendogram derived from UPGMA cluster analysis using morphological descriptors.

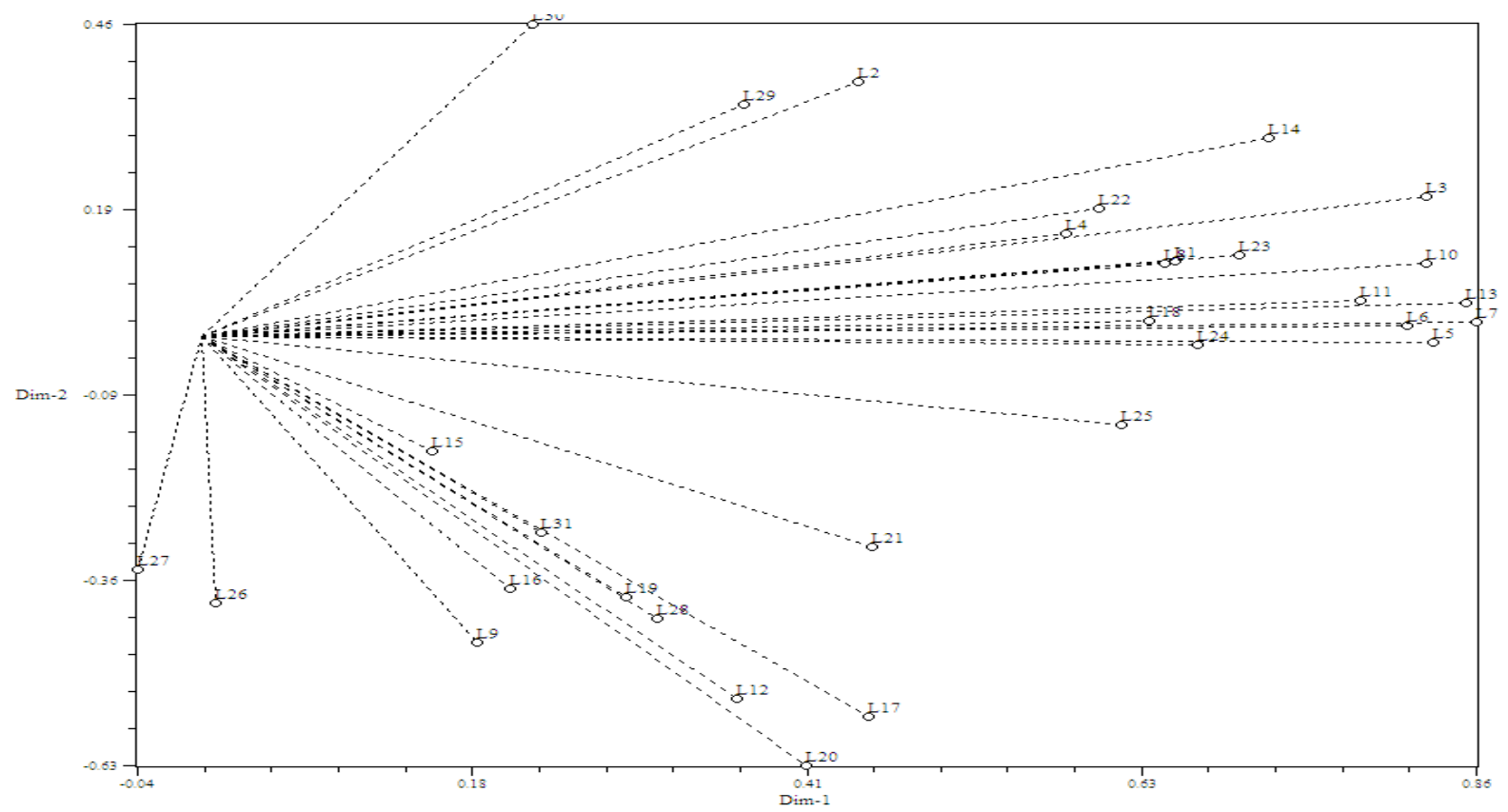

Fig.4. Two dimensional plot (with vector) of 31 germplasm lines of yellow sarson obtained using principal coordinate analysis (RAPD profiling).

ducible bands amplified against thirty-one yellow sarson germplasm lines. The total number of bands, average polymorphic bands, average percentage polymorphism and average polymorphic information content (PIC) was determined (Table 1).Molecular fingerprinting using RAPD marker is widely used for detecting genetic polymorphism between genotypes at the molecular level in many crop species viz oilseed crops, pulses and cereals crops. The number of polymorphic amplicons generated varied from 7(OPA-8) to 22(OPG -2) and presented molecular weight between 190bp to $9 \mathrm{~kb}$. From the RAPD primers, OPG-02 (Fig.7.), OPC09 and Operon-6 showed a higher level of genetic polymorphism among the germplasm line based on amplification of maximum no. of reproducible bands 22, 22 and 19 respectively while OPA-8 and Operon-8 showed the minimum no. of reproducible bands 7 and 9 respectively. Shengwu et al. (2003) also evaluated the genetic diversity of Brassica napus germplasm using 10 selected RAPD primers generated a total of 79 different polymorphic amplification in China.

In present study on molecular diversity analysis in yellow sarson germplasm lines, all the primer showed some unique loci (band) at a particular base pair (bp) size and differentiated the genotype from the rest of genotype present in germplasm. OPG-02 produced two unique bands in the PYSC-11-20 genotype of $190 \mathrm{bp}$ and in PYSC-11-30 genotype of 5kb (Fig.7.). OPC-9 


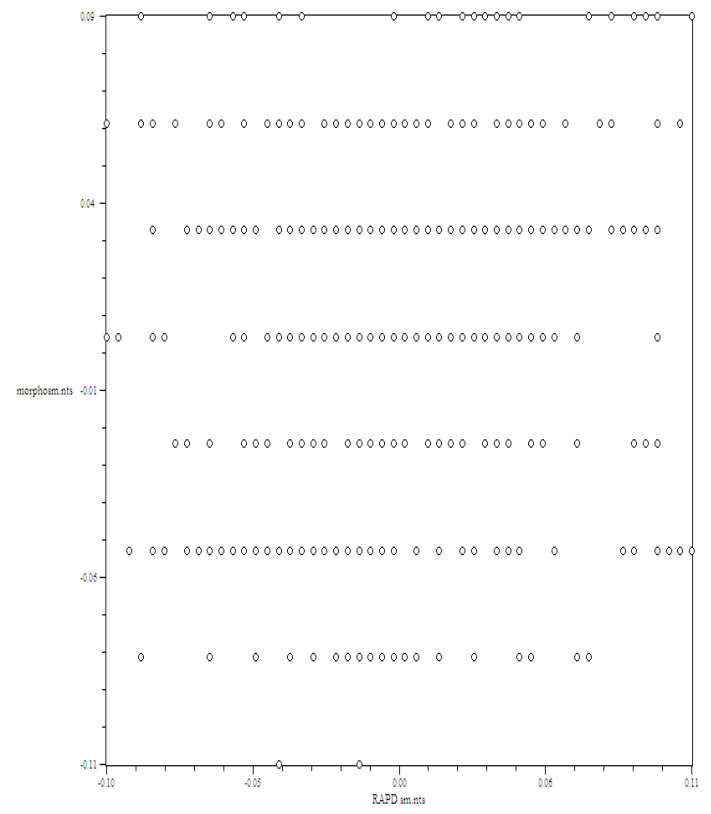

Fig. 5. Three dimensional plot (with vector) of 31 germplasm lines of yellow sarson obtained using principal coordinate analysis (RAPD profiling).

primer produced maximum numbers of the unique loci (6) present at the specific position in the germplasm lines were PYSC-11-36 (9000 bp and $6800 \mathrm{bp}$ ), B-9 (8000 bp), PYSC-11-25 (4000 bp), PPS-1 (2000 bp) and PYSC-11-35 (350 bp) (Fig.8). OPB-14 produced a single band of $900 \mathrm{bp}$ in PYSC-11-11 and primer OPA8 also produced unique band size of $300 \mathrm{bp}$ in PYSC11-35 genotype. PYSC-11-11 and PYSC-11-36 genotypes showed a maximum number of unique loci of different size. Ahmad et al. (2009) used RAPD marker for the study of DNA polymorphism in Brassica juncea at Pantnagar Uttrakhand. Gupta et al. (2012) also

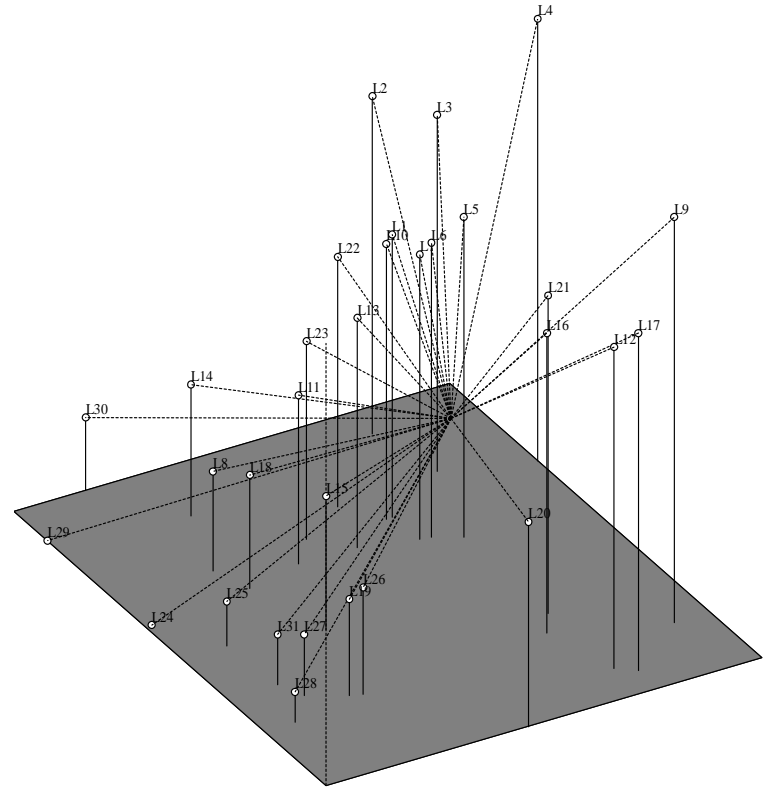

Fig. 6. Correlation matrix between morphological descriptors and RAPD profiling.

reported polymorphism among twenty varieties of Brassica juncea L. using ten RAPD markers. Ten RAPD primers generated 62 loci with 50 polymorphic and 12 monomorphic showing 6.2 loci per primer. Gupta et al. (2014) also used DNA-based primers RAPD and EST SSRs to identified Genetic variation in Indian mustard collected from different institutes of Northern India.

UPGMA cluster analysis using RAPD: The distance matrices based on the Jaccard similarity coefficient ranged from 0.557 to 0.899 . Based on the Jaccard similarity coefficient from the thirty-one yellow sarson germplasm lines PYSC-11-7 genotype showed maxi-

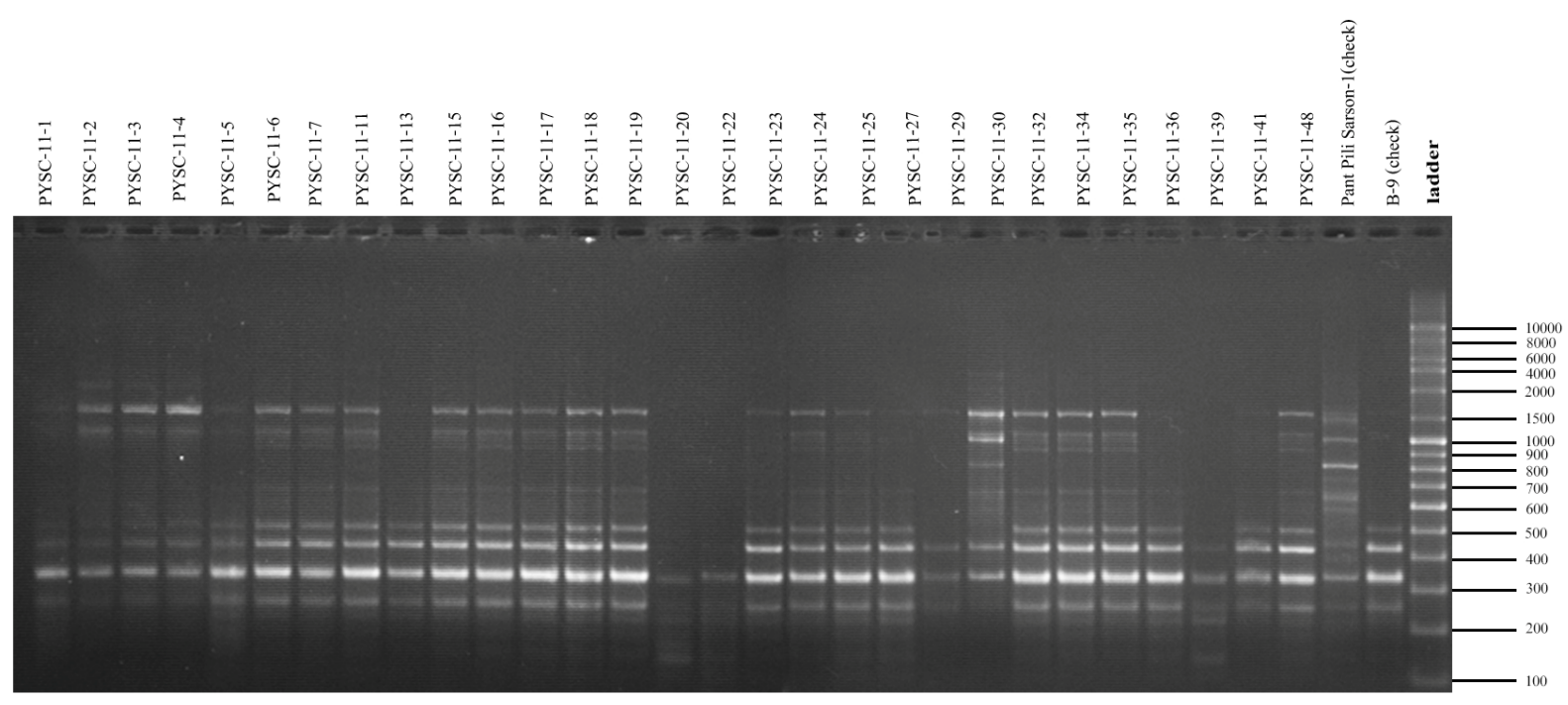

Fig. 7. PCR amplification of 31 yellow sarson genotypes with RAPD primer OPG 2. 
Harsha et al. / J. Appl. \& Nat. Sci. 8 (3): 1333 - 1340 (2016)

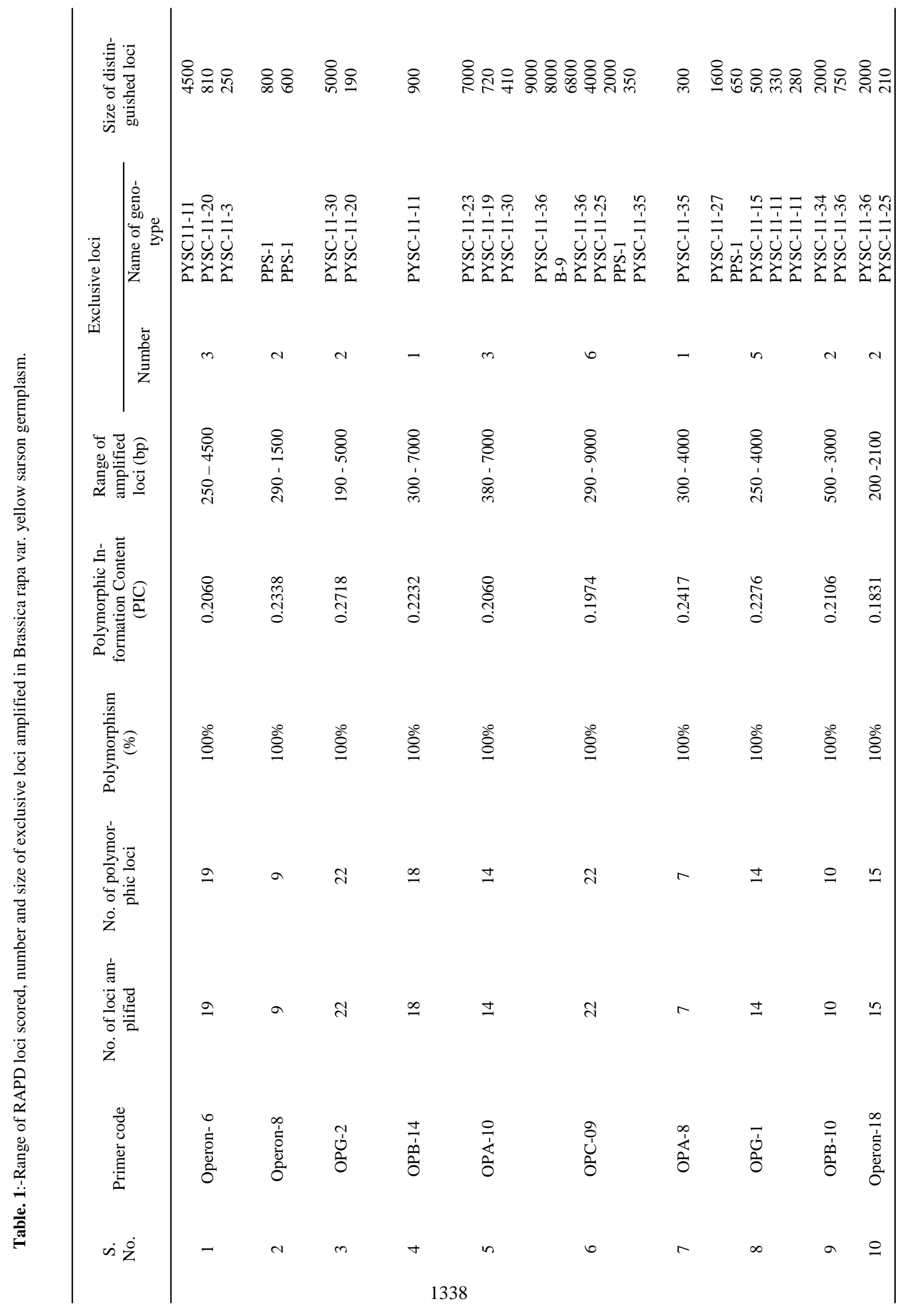




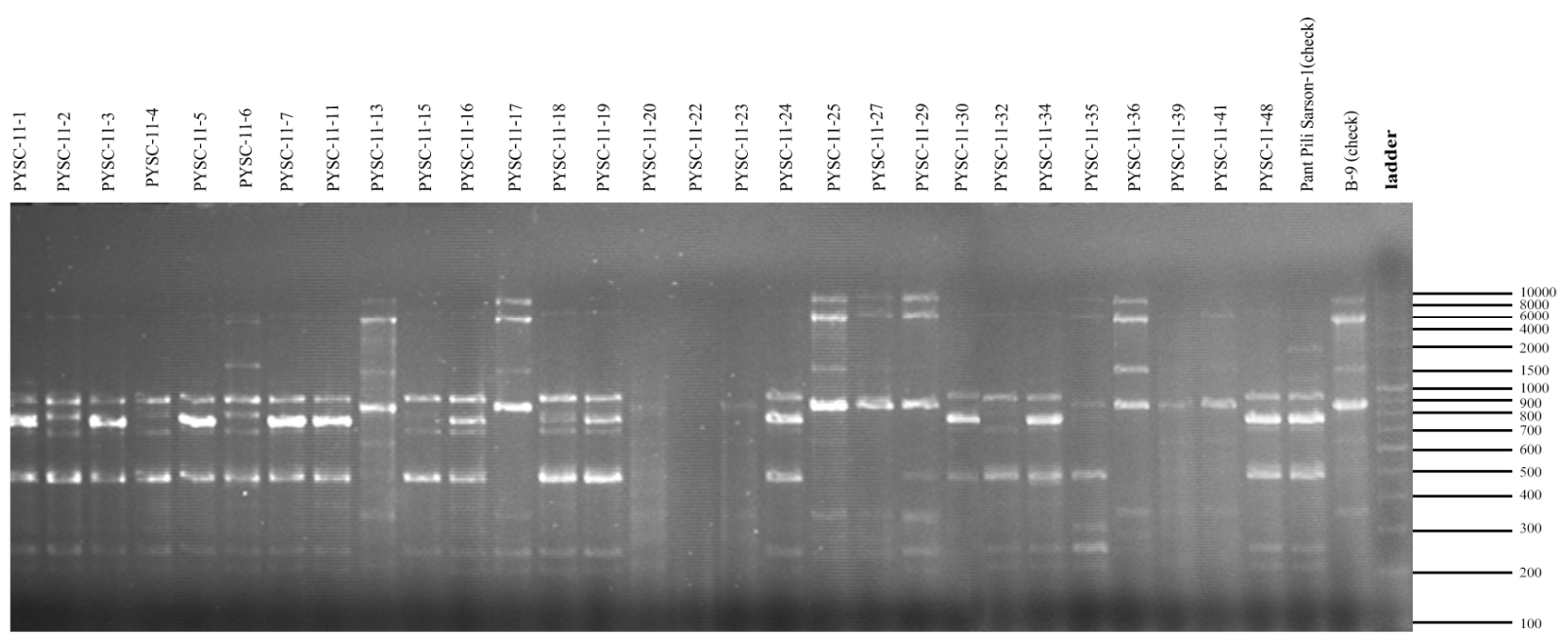

Fig. 8. PCR amplification of 31 yellow sarson genotypes with RAPD primer OPC 09.

mum resemblance $(89.9 \%)$ with the PYSC-11-5and PYSC-11-76 genotypes. PYSC-11-5 and PYSC-11-6 genotypes were $89.3 \%$ similar to each other. PYSC-11 -3 showed $89.3 \%$ and $88.6 \%$ similarity with the PYSC11-15 and PYSC-11-5 respectively. Minimum resemblance $(57.7 \%)$ found between PYSC-11-36 genotype with the PYSC-11-1 and PYSC-11-30 genotypes and $56.4 \%$ similarity with PYSC-11-18 genotypes. PYSC11-32 and PYSC-11-39 genotypes were found to 57\% similar (Fig.1.). Cluster analysis was done using UPGMA method and dendrograms were constructed (Fig.2.). Dendrogram based on the $\mathrm{J}$ distance matrix defined two major clusters for thirty-one yellow sarson germplasm lines based on $58 \%$ similarity. Cluster I comprised 12 yellow sarson genotypes viz; PYSC-1136, PYSC-11-39, PYSC-11-13, PYSC-11-25, B-9 (check), PYSC-11-23, PYSC-11-27, PYSC-11-41, PYSC-11-20, PYSC-11-22, PYSC-11-29 and PYSC11-17. Cluster II comprised of 19 yellow sarson genotypes viz; PYSC-11-48, PPS-1(check), PYSC-11-2, PYSC-11-4, PYSC-11-32, PYSC-11-30, PYSC-11-24, PYSC-11-34, PYSC-11-35, PYSC-11-16, PYSC-1111, PYSC-11-19, PYSC-11-15, PYSC-11-3, PYSC-11 -18, PYSC-11-6, PYSC-11-7, PYSC-11-5, and PYSC11-1. The germplasm lines present in the different cluster were diverse enough hence can be used as parental lines in a hybridization programme. RAPD data also analysed using principal coordinate analysis (PCA). Associations among the yellow sarson genotypes revealed by PCA were presented in two and three-dimensional plot and have shown the comparable result to some extent with the cluster analysis using UPGMA (Fig. 4 and 5).

Correlation between genetic variability of morphological descriptors and RAPD markers:The correlation between genetic variability of the morphological descriptor and RAPD analysis was found to be nonsignificant (Fig. 6) similar reports were also reported by Geleta and Labuschagne (2005), found a nonsignificant correlation between morphological characters and AFLP markers in sorghum. Gupta et al. (2012) studied the genetic relatedness among seventeen lines of Indian mustard at IARI, New Delhi using RAPD marker and morphological traits. For the study on genetic variability from the morphological descriptor and molecular analysis found a difference in the pattern of the cluster, might be due to the fact that molecular marker measure variation mainly in a noncoding sequence which probably have a minor impact on phenotype. Morphological descriptors, on the other hand, are affected by environmental conditions and show considerable variation (Gupta et al. 2012).

\section{Conclusion}

In conclusion, this study demonstrated that RAPD markers provide an effective tool for the assessment of genetic variation among yellow sarson germplasm and in line identification. This information could be used for selection of most divergent pairs of parents, which could be used for genetic linkage map construction in this species. Information on the genetic diversity in $B$. rapa var. yellow sarson germplasm can help breeder to select the best combinations, which produce a high level of heterosis. The observed genetic variation among investigated yellow sarson germplasm found in analysed loci should alter the breeders for introducing new genetic sources in a hybridization programme. Investigated collection includes a collection of yellow sarson germplasm lines from Eastern UP and Uttrakhand Hills. However, direct effort to diversify the genetic base of breeding material and to seek new sources of favourable alleles would be still necessary.

\section{REFERENCES}

Abbas, S.J., Khan, F., Marwat, B., Khan, I. A. and Munir, I. (2009). Molecular analysis of genetic diversity in bras- 
sica species. Pakistan Journal of Botany, 4: 167-176.

Ahmad, J., Mohd, A., Ram Bhajan and Khan, G.T. (2009). Assessment of Genetic Diversity and Genetic relationships among twenty varieties of Brassica juncea [L.] using RAPD markers. International J. of Biotechnology and Biochemistry, 5(1): 85-92.

Beckman, J.S. and Soller, M. (1983). Restriction fragment length polymorphism in plant genetic improvement: methodologies, mapping and costs. Theoretical and Applied Genetics, 67: 35-43.

Chen, S., Zou, W.A. Cowling and Meng, J. (2010). Allelic diversity in novel gene pool of canola quality Brassica napus enriched with alleles from B. Rapa and B. carinata. Crop Pasture Science, 61: 483-492.

Demeke, T., Adams, R.P. and Chibber, R. (1992). Potential Taxonomic use of random amplified polymorphic DNA: A case study in Brassica. Theoretical and Applied Genetics, 84: 990-994.

Divaret, I. and Thomas, G. (1998). Use of RAPD markers to analyse the genetic variability of a collection of Brassica oleracea L. In Thomas G, Monteiro AA (eds.): Proc. Int. Symp. Brassicas. Acta Hort. 459: 255-262..

Geleta, N. and Labuschagne, M.T. (2005). Qualitative traits variation in sorghum (Sorghum bicolor (L.) Moench) germplasm from eastern highlands of Ethiopia. Biodiversity and Conservation, 14: 3055-64.

Ghosh, K.K., Haque, M.E., Parvin, M.S., Akhter, F. and Rahim, M.M. (2009). Genetic diversity analysis in brassica varieties through RAPD markers. Bangladesh Journal of Agricultural Research. 34 (3): 493-503.

Gupta P.K., Varshney, R.K., and Sharma, P.C. (1999). Molecular markers and their applications in wheat breeding. Plant Breeding, 118: 369-390.

Gupta, R., Chandrashekhar, U.S., Yadav, J.B., Chakrabarty, S.K. and Dadlani, M. (2012). Assessment of genetic relatedness among Indian mustard (Brassica juncea) genotypes using morphological traits and DNA marker. The Indian Journal of Agricultural Sciences, 82(9): 746-752.

Gupta, N., Zargar, S.M., Gupta, Moni and Gupta, S.K. (2014). Assessment of Genetic Variation in Indian Mustard (Brassica juncea L.) Using PCR-Based Markers. Molecular Plant Breeding, 5(3): 10-179.

Karp, A., Kresovich, S., Bhat, K.V., Ayad, W.G. and Hodgkin, T. (1997). Molecular tools in plant genetic resources conservation: a guide to the technologies; in IPGRI Technical Bull. No. 2. International Plant Genetic Resources Institute, Rome, Italy.

Khan, W.M., Munir, I., Arif, F.M., Iqbal, A., Ali, I., Ahmad, D., Ahmad, M., Mian, A., Bakht, J. and Swati, Z.A. (2011). Genetic diversity analysis among Brassica juncea germplasm using RAPD markers. Africa Journal of Biotechnology, 10: 3654-3658.

Kresovich, S., Williams, J.G.K., McFerson, J.R., Routman, E.J. and Schaal, B.A. (1992). Characterization of genetic identities and relationships of Brassica oleracea $\mathrm{L}$. via a random amplified polymorphic DNA assay. Theoretical and Applied Genetics, 85: 190-196.

Mailer, R.J., Scarth, R. and Fristensky, B. (1994). Discrimination among cultivars of rapeseed (Brassica napus L.) using DNA polymorphism amplified from arbitrary primers. Theoretical and Applied Genetics, 87: 697-704.

Marshall, P., Marchand, M.C., Lisieczko, Z. and Landry,
B.S. (1994). A simple method to estimate the percentage of hybridity in canola (Brassica napus) F1 hybrids. Theoretical and Applied Genetics, 89: 853-858.

Misra, A.K. (2011) Variability for agromorphological traits in germplasm of yellow sarson (Brassica rapa L. var. yellow sarson). Cruciferae Newsletter, 30: 33-34.

Murry, H.C. And Thompson, W.F. (1980). Rapid isolation of high molecular weight plant DNA. Nucleic Acid Research, 8: 4321-4325.

Quiros, C.F., Hu, J., This, P., Cherve and Delseny, M. (1991). Developmental and chromosomal localization of genomespecific markers by the polymerase chain reaction. Theoretical and Applied Genetics, 82: 627-632.

Ren, J., McFerson, J.R., Li, R., Kresovich, S. and Lamboy, W.F. (1995). Identities and relationships among Chinese vegetable Brassicas as determined by random amplified polymorphic DNA markers. Journal of American Society for Horticultural Science, 120: 548-555.

.Saha, S., Molla, R., Chandra, D. and Rahman, L. (2008). Assessment of genetic variation and relationships within the varieties of four Brassica species by RAPD markers. Australian Journal of Crop Science, 2: 105-114.

Santos, J.B., Nienhuis, J., Skroch, P., Tivang, J. and Slocum, M.K. (1994). Comparison of RAPD and RFLP genetic markers in determining genetic similarity among Brassica oleracea L. genotypes. Theoretical and Applied Genetics, 87: 909-915.

Shengwu, H., Ovesna, J., Kucera, L., Kucera, V. and Vyvadilova, M. (2003). Evaluation of genetic diversity of Brassica napus germplasm from China and Europe assessed by RAPD markers. Plant Soil and Environment, 49: 106-113.

Tautz, D. (1989). Hypervariability of simple sequences as general sources for polymorphic DNA markers. Nucleic Acids Reserch, 17(16): 6463-6471.

Thormann, C.E., Ferreira, M.E., Camargo, L.E.A., Tivang, J.G. and Osborn, T.C. (1994). Comparison of RFLP and RAPD markers to estimating genetic relationships within and among Cruciferous species. Theoretical and Applied Genetics, 88: 973-980.

Vos, P., Hogers, R., Bleeker, M., Reijans, M., Lee, T.V.D., Hornes, M., Frejters, A., Pot, J., Peleman, J., Kuiper, M. and Zabeau, M. (1991). AFLP a new technique for DNA fingerprinting. Nucleic Acid Research, 23: 4407-4414.

Williams, J.G.K., Kubelik, A.R., Livak, K.J., Rafalski, J.A. and Tingey, S.V. (1990). DNA polymorphisms amplified by arbitrary primers are useful as genetic markers. Nucleic Acid Research, 18: 6531-6535.

Welsh, J. and McClelland, M. (1990). Fingerprinting genomes using PCR with arbitrary primers. Nucleic Acids Research, 18: 7213-7218.

Yassein, A.A.M., Abdal-Aziz, S.A. and Galab, K.H. (2013). Evaluation of Genetic diversity and heritability of some rapeseed (Brassica napus) genotypes using agronomical and molecular traits. Journal of Advanced Laboratory Research in Biology, 4(4): 131-134.

Yousuf, M., Bhat, T.M. and Kudesia, R. (2012). Comparative genetic diversity studies in mustard (Brassica Juncea) varieties using randomly amplified polymorphic DNA (RAPD) analysis. African Journal of Biotechnology, 12: 3430-3434. 